\title{
Call for Papers, Issue 3/2021
}

\author{
Energy Informatics
}

\author{
Philipp Staudt $\cdot$ Sebastian Lehnhoff $\cdot$ Richard Watson
}

Published online: 4 October 2019

(c) Springer Fachmedien Wiesbaden GmbH, ein Teil von Springer Nature 2019

\section{Special Issue}

Energy Informatics is based on the precept that adding information engineering to the energy domain increases energy efficiency and renewable energy utilization, and reduces associated carbon emissions [Energy + Information < Energy (Watson et al. 2010)]. Information engineering in this context is the practice of information processing and engineering with methods from computer science, information systems, information technology, and statistics. Scholars from these disciplines are well-positioned to have a significant impact on the successful transition to a renewable energy society operated at high levels of energy efficiency. The energy domain encompasses, among other areas, the management and operation of generation facilities, infrastructure, or the consumption processes. The pressing societal challenge to create an efficient renewable society is a grand opportunity for informatics scholars to apply their systems thinking skills and information technology knowledge to make a significant contribution to this information-intensive problem. Particularly, because energy transition requires the acquisition, processing, and analysis of sector-relevant data to

\section{P. Staudt $(\square)$}

Research Group Smart Grids \& Energy Markets, Karlsruhe Institute of Technology, Karlsruhe, Germany

e-mail: philipp.staudt@kit.edu

\section{S. Lehnhoff}

Chair of Energy Informatics, Carl von Ossietzky University

Oldenburg, Oldenburg, Germany

e-mail: sebastian.lehnhoff@offis.de

R. Watson

Terry College, University of Georgia, Athens, GA, USA

e-mail: rwatson@terry.uga.edu optimize all processes along the value chain of a highly dynamic and continuously changing energy system.

Fossil-fuel based energy generation is one of the major origins of greenhouse gases and contributes largely to global warming. Consequently, many members of the international community have agreed to reduce their carbon footprint dramatically over the next decades. The decarbonization of energy systems is therefore an objective for many countries and organizations. This comes with a variety of challenges. Major renewable sources, such as solar and wind, are intermittent, and it is a challenge to balance supply and demand at all times. Additionally, power grids are not equipped to deal with peaks in renewable generation, and power systems without sufficient conventional generation are not prepared for corresponding troughs. These are just a few examples of the challenges to create an energy system that is run without fossil fuel (Taylor et al. 2016).

A decarbonized energy system needs to be supported by advanced information and communication systems, which need to be developed, tested, and interconnected. This affects the entire value chain of the energy system. Therefore, this issue addresses topics that are at the intercept of engineering, economics, information systems, and information technology at all levels of the energy system, from generation to national policy, that are embraced by Energy Informatics.

One major technological development that may aid in the transition to a more sustainable energy system is its ongoing digitalization. The increasing use of smart meters enables a better understanding of customer behavior for residential, commercial, and industrial consumers. Furthermore, they could be used to monitor organizational and household energy consumption in real-time. Additionally, a variety of energy related system data is publicly available 
allowing for the development of software that can aid in the management of energy systems. Artificial intelligence and data analytics can be used to extract value from available data. These methods, can, for example, be applied to energy markets to handle demand and supply fluctuations, find an optimal marketing strategy, and to minimize energy procurement costs. Therefore, energy informatics research needs to combine the perspectives of electrical engineering, energy economics, and information technology.

In its course, the renewable energy transition may strongly affect residential households. Electricity is a commodity that needs to be available at all times, though not always available for all purposes (e.g., charging an electric vehicle) and households are often not aware of the implications of their behavior. However, households can become empowered regarding their energy use through smart meters as well as through the decreasing price for decentralized small-scale energy generation units, such as solar panels, and the decreasing costs for electrical storage capacity. Furthermore, increasing market penetration by electric vehicles might strongly change residential consumption patterns. It is therefore highly important to develop strategies and tactics for households that allow them to optimally use their available resources and monetize their flexibility, such as when they charge their electric vehicle or operate heating and cooling systems. This can be achieved through information systems designed in a way that consumers retain ultimate control and that complexity is manageable. This includes information systems that support local market designs where prosumers and consumers can trade. In turn, such household optimization also has distributional effects within societies as network tariffs are often volume-based and are therefore distributed among fewer consumers. Large consumers might develop demand and supply-side management strategies to reduce their energy costs and thereby contribute to grid stability. While many authors have considered this in theory, it is still unclear whether such strategies would be used in practice or, in other words, if the expected financial benefits are sufficient for such strategies to be adopted at scale.

For renewable generators, it will be important to develop long-term marketing strategies to reduce their market risk under the uncertainty of volatile generation, prices, and weather. Using historical weather patterns for demand and supply planning might be problematic given that climate change can make extreme weather conditions more common. There is a need to rethink how to forecast short- and long-term demand and supply and examine the potential to apply AI methods that can learn from recent events.

Beyond the generation and consumption of electricity, other energy sectors also need to be decarbonized such as heat or mobility. This includes grid and market integration of electric vehicles, power-to-gas technologies, and the provision of heat and cooling services. All of these areas require a careful online-optimization using forecasting techniques and an economic sizing of the needed energy infrastructure and storages.

Energy systems need to be carefully operated. System operators usually acquire ancillary services such as balancing or reactive power to ensure a stable grid condition. The intermittency of renewable energy will likely increase the need for these services. Furthermore, power system congestion might stimulate the need for new solutions such as dynamic line ratings or optimal switching protocols. All of these areas can be supported using advanced information systems and corresponding data.

Finally, the transition to a digitalized renewable energy system needs a communication structure. This includes the communication of current and immediate future demand and supply, ideally the generation (e.g., a windmill) and consumption unit (an appliance in a household), as well as grid state variables and other system-related data. Such an information-intensive system needs to be designed and the wide range of relevant stakeholders needs to be engaged in the process. Furthermore, privacy, data and national security issues need to be addressed.

This special issue welcomes a diversity of submissions and research methods that deliver applicable knowledge because the transition to a renewable society is in urgent need of implementable practices.

In their submission, authors should clearly state the problem they address, why it is important, and how their research creates applicable knowledge.

\section{Submission Guidelines}

Please submit papers by 1 July 2020 at the latest via the journal's online submission system (http://www.editor ialmanager.com/buis/). Please observe the instructions regarding the format and size of contributions to Business \& Information Systems Engineering (BISE). Papers should adhere to the submission general BISE author guidelines (http://www.bise-journal.com/author_guidelines).

All papers will be reviewed anonymously (double-blind process) by at least two referees with regard to relevance, originality, and research quality. In addition to the editors of the journal, including those of this special focus, distinguished international professionals with scientific and practical backgrounds will be involved in the review process. 


\section{Schedule}

Paper submission due

Notification of authors

1 July 2020

1 September

2020

Revision due

2 November

2020

Notification of authors

16 December

2020

Completion of a second revision (if needed)

Anticipated publication date
21 January 2021

June 2021

\section{References}

Buchmann E, Kessler S, Jochem P, Böhm K (2013) The costs of privacy in local energy markets. In: IEEE 15 th conference on business informatics, Vienna. IEEE, pp 198-207. https://doi.org/ 10.1109/cbi.2013.36

Dalén A, Krämer J (2017) Towards a user-centered feedback design for smart meter interfaces to support efficient energy-use choices. Bus Inf Syst Eng 59(5):361-373

Fridgen G, König C, Häfner L, Sachs T (2016) Providing utility to utilities: the value of information systems enabled flexibility in electricity consumption. J Assoc Inf Syst 17(8):537

Goebel C, Jacobsen HA, del Razo V, Doblander C, Rivera J, Ilg J, Lehnhoff S, Appelrath HJ et al (2014) Energy informatics. Bus Inf Syst Eng 6(1):25-31

Goel S (2015) Anonymity vs. security: the right balance for the smart grid. In: CAIS, vol 36, :Article 2. https://doi.org/10.17705/1cais. 03602

Hu J, Vasilakos AV (2016) Energy big data analytics and security: challenges and opportunities. IEEE Trans Smart Grid 7(5):2423-2436

Kossahl J, Busse S, Kolbe LM (2012) The evolvement of energy informatics in the information systems community - a literature analysis and research agenda. In: Proceedings of the European conference on information systems, p 172

Marrone M, Hammerle M (2018) Smart cities: a review and analysis of stakeholders' literature. Bus Inf Syst Eng 60(3):197-213

Molzahn DK, Dörfler F, Sandberg H, Low SH, Chakrabarti S, Baldick R, Lavaei J (2017) A survey of distributed optimization and control algorithms for electric power systems. IEEE Trans Smart Grid 8(6):2941-2962. https://doi.org/10.1109/TSG.2017. 2720471

Muthirayan D, Kalathil D, Poolla K, Varaiya P (2019) Mechanism design for demand response programs. IEEE Trans Smart Grid. https://doi.org/10.1109/TSG.2019.2917396

Nieße A, Lehnhoff S, Tröschel M, Uslar M, Wissing C, Appelrath HJ, Sonnenschein M (2012) Market-based self-organized provision of active power and ancillary services: an agent-based approach for smart distribution grids. In: Proceedings complexity in engineering. IEEE, pp 1-5. https://doi.org/10.1109/compeng. 2012.6242953

Paukstadt U, Gollhardt T, Blarr M, Chasin F, Becker J (2019) A taxonomy of consumer-oriented smart energy business models. In: Proceedings of the 27th European conference on information systems, Stockholm

Sheikh I, Callaway D (2019) Decarbonizing space and water heating in temperate climates: the case for electrification. Atmosphere 10(8):435

Taylor JA, Dhople SV, Callaway DS (2016) Power systems without fuel. Renew Sustain Energy Rev 57:1322-1336

Wang Y, Chen Q, Hong T, Kang C (2018) Review of smart meter data analytics: applications, methodologies, and challenges. IEEE Trans Smart Grid 10(3):3125-3148

Warkentin M, Goel S, Menard P (2017) Shared benefits and information privacy: what determines smart meter technology adoption? J Assoc Inf Syst 18(11):3

Watson RT, Boudreau MC, Chen AJ (2010) Information systems and environmentally sustainable development: energy informatics and new directions for the IS community. MIS Q 34(1):23-38

Wunderlich P, Veit DJ, Sarker S (2019) Adoption of sustainable technologies: a mixed-methods study of German households. MIS Q 43(2):673-691 